Research Article

\title{
Surrounding Rock Stability Classification Method of Coal Roadway Based on In Situ Stress
}

\author{
Yongjie Yang $\mathbb{D}^{D}$, Gang Huang $\mathbb{D}$, and Lingren Meng \\ State Key Laboratory of Mining Disaster Prevention and Control Co-Founded by Shandong Province and the Ministry of Science \\ and Technology, Shandong University of Science and Technology, Qingdao 266590, China
}

Correspondence should be addressed to Gang Huang; huanggang@sdust.edu.cn

Received 20 October 2021; Accepted 26 November 2021; Published 15 December 2021

Academic Editor: Gaofeng Song

Copyright ( 2021 Yongiie Yang et al. This is an open access article distributed under the Creative Commons Attribution License, which permits unrestricted use, distribution, and reproduction in any medium, provided the original work is properly cited.

In situ stress is one of the most important factors affecting surrounding rock stability classification of coal roadway. Most surrounding rock stability classification methods do not fully consider the influence of in situ stress. In this paper, the author applied a fuzzy clustering method to the classification of surrounding rock stability of coal roadway. Taking into account the complexity of the classification of surrounding rock, some factors such as the strength of surrounding rock, in situ stress, the main roof first weighting interval, the size of the chain pillar, and the immediate roof backfilled ratio are selected as the evaluation indexes. The weight coefficients of these evaluation indexes are determined by unary regression and multiple regression methods. Using fuzzy clustering and empirical evaluation method, the classification model of surrounding rock stability of coal roadway is proposed, which is applied to 37 coal roadways of Zibo Mining Group Ltd., China. The result is in good agreement with practical situation of surrounding rock, which proves that the fuzzy clustering method used to classify the surrounding rock in coal roadway is reasonable and effective. The present model has important guiding significance for reasonably determining the stability category of surrounding rock and supporting design of coal roadway.

\section{Introduction}

Coal mines are dominated by underground mining in China. The total length of new driving roadways in coal mines is up to thousands of kilometres per year in China, of which more than $80 \%$ are coal roadways and coal-rock roadways [1]. After excavation, if there is no timely support, surrounding rock of coal roadway is likely to instable failure. Due to the complexity of mining activities, the design of the support for the coal roadway must be based more on the evaluation and classification of the stability of the surrounding rock stability. As a basis for the control of the surrounding rock on the roadway, the stability of the evaluation of the surrounding rock stability has been widely studied by scholars.

It is of great significance to determine a simple and accurate method for classifying surrounding rock; many classification methods for surrounding rock have been proposed, including single factor classification (RQD [2-4]) and multifactor classification (RMR [5, 6], GSI [7], and Q-system $[8,9])$. In recent years, the most widely studied classification methods are based on fuzzy mathematics, analytic hierarchy process (AHP), artificial neural networks (ANN), and support vector machines (SVM), etc. Shi et al. [10] adopted comprehensive assigning method to determine the weights of evaluation indexes based on fuzzy analytic hierarchy process (FAHP), and the FAHP model is established for optimized classification of surround rock. Hasegawa et al. [11] used ANN to classify the surrounding rock of mountain tunnels by collecting geophysical datasets at a tunnel face and surrounding rock, but complete surrounding rock data were difficult to obtain. Deng et al. [12] established a BP-ANN classification model for surrounding rock stability of coal roadway in MATLAB environment and applied the model to 13 coal roadway data samples for testing. Li et al. [13] established a highway tunnel classification model based on the SVM theory of particle swarm optimization, and the surrounding rock mass of the tunnel 
was divided into five grades. Zheng et al. [14] presented a new reliability rock mass classification method based on a least squares support vector machine (LSSVM) optimized by a bacterial foraging optimization algorithm (BFOA), which can improve the classification accuracy of surrounding rock exhibiting randomness. Furthermore, Wang et al. [15] applied the ideal point method to the classification of surrounding rock stability and considered the influence of groundwater of the tunnel surrounding rock. Wang et al. [16] proposed a novel model to analyse the surrounding rock stability based on set pair analysis (SPA). Based on uncertainty measure theory, He et al. [17] established a stability classification and order-arranging model of surrounding rock. Based on D-S evidence theory and error-eliminating theory, Wu et al. [18] proposed a model for evaluation of underground engineering surrounding rock stability and used four kinds of weighting methods to avoid the difference of single weighting method in calculating index weight.

Although these methods have enabled numerous achievements in the classification of surrounding rock, some shortcomings still exist. In dealing with uncertain problems, the analytic hierarchy process is greatly affected by personal subjective factors, it is difficult to artificial neural networks to find suitable learning algorithms, and support vector machines are inefficient when processing a large number of samples. The stability of the surrounding rock of the roadway is a complex problem that is affected by many factors, and the influence of various factors on the stability of the surrounding rock has a considerable degree of randomness and fuzziness, so the boundary between the stability categories of the surrounding rock is often not clear. Since the classification of the stability on the surrounding rock of the roadway is a fuzzy concept, it is quite effective to choose fuzzy clustering when dealing with the classification of the stability of the surrounding rock on the roadway, which has many influencing factors and strong ambiguity.

In the selection of classification evaluation indexes, most classification methods consider the influence of rock mass structure, the degree of development of joints and cracks, and their properties on the stability of surrounding rock, but it is difficult to determine parameters such as the degree of joints and cracks on-site, and the operability is poor. When considering the influence of in situ stress on the stability classification of surrounding rock, the depth of the roadway is mostly used to represent the influence of in situ stress, or according to the relationship between the weight of the overlying strata and the strength of the rock mass $[19,20]$, the in situ stress is divided into high stress zone and low stress zone, and then a stress state influence correction factor is considered. Some researchers consider the influence of the initial in situ stress and use a converted in situ stress to represent the initial. The converted stress is only an average of the three principal stresses. The value does not consider the influence of the angle between the horizontal in situ stress and the direction of the roadway on the stability of the surrounding rock. The application of initial in situ stress in the surrounding rock stability classification of roadway is not reasonable and complete; in particular there is no effective method to determine the magnitude and direction of vertical and maximum (or minimum) horizontal in situ stress near the roadway. In particular, the influence of horizontal in situ stress on the stability of the surrounding rock of the roadway should be studied. When the long axis direction of roadway is parallel to the maximum horizontal in situ stress, the influence is the smallest, which is the most favorable for the stability of roof and floor. When the long axis direction of roadway is perpendicular to the maximum horizontal in situ stress, it is most unfavorable to the stability of roof and floor. In the roadway oblique to the maximum horizontal principal stress at a certain angle, the stress concentration occurs on one rib of the roadway and the stress release occurs on the other rib, so the deformation and failure of the roof (or floor) will be biased towards one rib of the roadway.

It can be seen from the above analysis that the influence of in situ stress on the stability of the surrounding rock of the roadway must be considered, especially the influence of the horizontal in situ stress on the stability of the surrounding rock of the coal roadway. Combined with the fuzzy clustering, the author proposes a SIM-based classification method for surrounding rock stability of coal roadway: SIM, i.e., the strength of surrounding rock, in situ stress, and mining indexes. This method uses site monitoring or laboratory tests to determine the values of evaluation indexes, and the weights of each evaluation index are determined by regression analysis and fitting methods, which are more reliable and accurate. Furthermore, the fuzzy clustering is adopted to classify the coal roadways to determine the surrounding rock grade.

\section{Determination of the Evaluation Indexes of the Surrounding Rock Stability in Coal Roadway}

The stability of the surrounding rock of a coal roadway depends on the internal stress, the physical and mechanical properties, and the interaction between the two. The internal stress of the surrounding rock depends on the in situ stress, the shape and size of the roadway, the influence of excavation and mining, the support strategy, and others. The physical and mechanical properties of the surrounding rock refer to the strength and physical characteristics of the surrounding rock, including the physical and mechanical parameters of the roof, floor, and rib, and the parameters of the rock blocks, the structure of the rock mass, and the bedding joints and fractures. In addition, the influence of groundwater and time must also be considered. The main factors that affect the stability of the surrounding rock on the coal roadway are shown in Table 1.

The surrounding rock stability classification of coal roadway is supposed to be based on the characteristics of sedimentary rock (and local igneous rock) in coal mine, which requires clear physical meaning of evaluation index, easy access to parameters, simple classification method, and strong practicability. Therefore, the biggest factors affecting the stability of the roadway surrounding rock in Table 1 are screened out, and the factors that have no significant effect 
TABLE 1: The factors affecting surrounding rock stability of coal roadway.

\begin{tabular}{lcc}
\hline No. & Type & Factor \\
\hline 1 & & Strength of main roof \\
2 & Strength & Strength of immediate roof \\
3 & Strength of coal seam & Strength of immediate floor \\
4 & & Coal mining method \\
5 & In situ stress & Magnitude \\
6 & & Angle \\
7 & Roadway characteristics & Height \\
8 & & Width \\
9 & Coal seam geological characteristics & Buried depth \\
10 & & Thickness \\
11 & Thickness of roof and floor & Dip angle \\
12 & & Buried depth \\
13 & & Main roof \\
14 & & Immediate roof \\
15 & Abutment pressure characteristics & Immediate floor \\
16 & & Immediate roof first caving interval \\
17 & & Main roof first weighting interval \\
18 & Groundwater & Main roof periodic weighting interval \\
19 & Time & \\
20 & &
\end{tabular}

on the stability are ignored. The initial selected evaluation indexes include the comprehensive strength of surrounding rock, in situ stress, the immediate roof backfilled ratio, the main roof first weighting interval, and the chain pillar size of coal roadway. Among them, the comprehensive strength of surrounding rock is divided into the strength of roof, floor, and rib. In situ stress is divided into vertical and horizontal in situ stress. The immediate roof backfilled ratio, the main roof first weighting interval, and the chain pillar size of coal roadway are called mining index.

2.1. Comprehensive Strength of Surrounding Rock. The surrounding rock of the roadway includes the roof, floor, and rib, and the roof includes the immediate roof and the main roof, and under some conditions there is a false roof, and the floor includes the immediate floor and the main floor. For the coal roadway, the ribs are coal seam, but when the coal seam is thin, the ribs also cover part of the rock strata. To reasonably characterize the strength of surrounding rock, the concept of comprehensive strength of surrounding rock is proposed, which covers the comprehensive strength of the roof, floor, and rib. The thickness of each rock stratum, the thickness of the coal seam, and the strength of the coal and rock in each stratum are comprehensively considered. When calculating the comprehensive strength of surrounding rock, the strength of rock block is determined first, then the strength of rock mass is calculated, and finally the comprehensive strength is calculated. Since the strength of the rock block can usually be obtained directly through the laboratory test, the calculation of the rock mass strength and the comprehensive strength is introduced only introduced in the following.

The strength and the structural parameters of the rock mass (i.e., layered thickness, joint fracture spacing, etc.) are considered when calculating the rock mass strength. The rock mass strength is obtained from laboratory experiments, while the structural parameters of the rock mass can be expressed by the rock mass strength coefficient $K_{r m}$ (equation (1)) [21].

$$
K_{r m}=\frac{R_{r m}}{R_{r b}},
$$

where $R_{r m}$ represents the uniaxial compressive strength of the rock mass, MPa. $R_{r b}$ represents the uniaxial compressive strength of rock block, MPa.

Therefore, it is easy to obtain the rock mass strength when the rock block strength and the rock mass strength coefficient are known. Owing to the influence of the thickness, structure, bedding, joint, and fracture spacing of the rock mass, the parameters of the rock mass strength index are difficult to obtain, so it is difficult to apply on site. He et al. [22-24] proposed an improved discontinuous deformation analysis (DDARF) method to achieve the simulation of the joint distribution by performing a numerical simulation of the deformation and fracture processes of the surrounding rock. However, this method requires special petrographic measurement techniques and image processing methods. Therefore, a method to estimate the rock mass strength index based on the stratigraphy column is proposed, which is corrected by numerical simulation and on-site testing, so that the rock mass strength index is more accurate and convenient to use. According to the characteristics of the description of the rock mass structure characteristics in the stratigraphy column, the weight of each factor (degree of joint fracture, bedding, filling, and cementation) is determined using the analytic hierarchy process (equation (2)), so the rock mass strength index can be obtained.

$$
K_{r m}=\alpha J_{n}+\beta B_{n}+\gamma J_{f},
$$


where $K_{r m}$ is the rock mass strength coefficient. $J_{n}$ is the development degree of joints. $B_{n}$ is the development degree of beddings. $J_{f}$ is the development degree of cemented filling. $\alpha$ is the weight of joints. $\beta$ is the weight of beddings. $\gamma$ is the weight of cemented filling.

After determining the rock strength of each rock strata, the comprehensive strength of surrounding rock of roadway can be calculated by weighted average (equation (3)) according to rock thickness. The comprehensive strength of the roof is weighted average according to the strength of each rock strata in the range of two times the height of the roadway, the floor is weighted average in the range of one time the height of the roadway, and the comprehensive strength of the rib is weighted average according to the strength of each coal and rock strata in the height of the roadway.

$$
R=\frac{\sum_{i=1}^{n} M_{i} \cdot r_{i}}{\sum_{i=1}^{n} M_{i}}
$$

where $R$ represents the comprehensive strength of the surrounding rock. $M_{i}$ represents the thickness of the i-th layer of surrounding rock. $r_{i}$ represents the rock strength of the i-th layer of surrounding rock.

2.2. In Situ Stress Index. The initial in situ stress is the main factor to be considered in the classification of the stability of the surrounding rock of the roadway. However, due to the large workload of in situ stress measurement, high technical requirements, and high testing costs, only a limited number of representative locations can be selected for testing according to the geological structure characteristics of the mine area, and it is difficult to infer the magnitude and direction of the in situ stress near each roadway from the data of a limited number of in situ stress measurement points in the mine area.

Therefore, based on the results of many initial in situ stress measurements, the relationship between the buried depth of the measuring point and the vertical in situ stress and the maximum (minimum) horizontal in situ stress is established (Figure 1), so that the magnitude of the three initial in situ stresses can be preliminarily determined from the buried depth. Then according to the measured in situ stress, combined with the geological structure and movement law of the mine, determine the horizontal in situ stress direction, and then consider the angle between the horizontal in situ stress and the long axis direction and the buried depth of the roadway to determine the vertical and horizontal in situ stress. The classification results of surrounding rock stability are more scientific and reliable by considering vertical stress and horizontal stress of rib in roadway classification.

According to the relevant knowledge of geology, the direction of horizontal in situ stress is relatively stable in a large tectonic area. Therefore, the maximum and minimum horizontal in situ stress directions at various stress measurement points can be used to indicate the direction of the maximum and minimum horizontal in situ stresses of the nearby roadway. Then, according to the direction of the angle between the roadway heading direction and the horizontal stress direction, the horizontal stress of the rib of roadway can be calculated.

2.3. Mining Index. For the roadway, it will inevitably be affected by the abutment pressure produced by the mining of the coal face, and in some cases, mining activity is the main factor that affects the stability of the surrounding rock of the roadway. The width of the coal pillar of the roadway, the main roof first weighting interval, and immediate roof backfilled ratio are selected as the main factors affecting the mining and at the same time as the evaluation indexes of the stability of the surrounding rock of the roadway.

2.3.1. The Chain Pillar of the Roadway. Depending on the width of the chain pillar and the layout of the roadway, the chain pillar can be divided into four categories: the gob-side entry retained coal pillar, the gob-side entry coal pillar, the wide coal pillar, and the strip coal pillar $[25,26]$. Because the working face of 37 sample entries is mostly coal mining under buildings, strip-mining stopping is used. The chain pillars are mostly strip coal pillars, so gob-side retained entry (and gob-side entry) is rarely used, and statistical laws cannot be formed. Therefore, in the working face of gob-side retained entry (and gob-side entry), the surrounding rock category is degraded by 1-2 categories.

2.3.2. The Immediate Roof Backfilled Ratio N. The immediate roof backfilled ratio $N$ reflects the filling degree of gob after immediate roof breaking. The larger the immediate roof backfilled ratio is, the smaller the subsidence of the main roof is, and the slower the stope abutment pressure appears, and on the contrary, the stronger the stope abutment pressure appears. Therefore, it is selected as one of the classification indexes of roadway surrounding rock stability.

2.3.3. The Main Roof First Weighting Interval $C_{0}$. The main roof first weighting interval $C_{0}$ reflects the intensity of the abutment pressure behaviour of the stope. The larger the main roof first weighting interval is, the stronger the abutment pressure behaviour of the stope is, and the greater the impact on the stability of the surrounding rock of the roadway is. In contrast, the smaller the main roof first weighting interval is, the weaker the abutment pressure behaviour of the stope is, and the less obvious the impact on the stability of the surrounding rock of the roadway is.

\section{Determination of the Weight of the Classification Index}

The surface displacement of surrounding rock is one of the important factors to reflect the stability, which includes roofto-floor displacement and rib-to-rib displacement. In order to eliminate the influence of roadway size, the author uses the displacement convergence to reflect the surrounding rock stability, which also includes the roof-to-floor and ribto-rib displacement convergence. The eight surrounding 


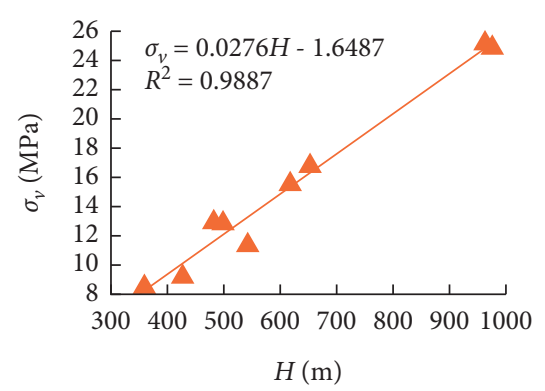

(a)

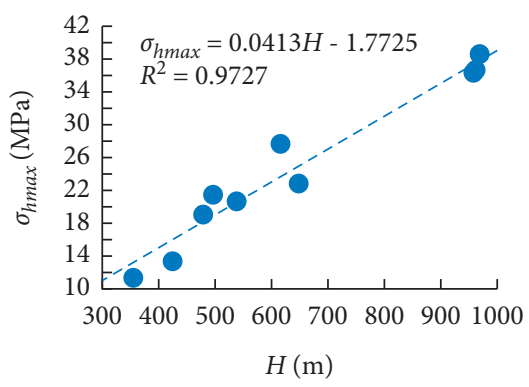

(b)

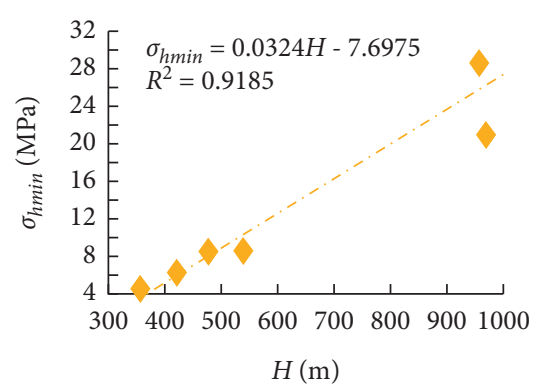

(c)

Figure 1: Statistical relationship between in situ stress and buried depth.

rock stability evaluation indexes have different degrees of influence on the overall stability. There are primary and secondary distinctions. Because the evaluation index of chain pillar type cannot be characterized by numerical value, when determining the influence of this index on the surrounding rock stability, the strength of surrounding rock should be degraded (or not degraded) according to the chain pillar type and then classified according to the strength of surrounding rock after change. Therefore, only the weights of the remaining seven indicators need to be determined. According to the statistical data of on-site ground pressure of roadway, the regression analysis of each classification index is carried out by using the unary nonlinear regression method, and the relationship curve between each evaluation index and the roof-to-floor (rib-to-rib) displacement convergence is obtained, so as to determine the quantitative relationship between each evaluation index and the surrounding rock stability.

3.1. Unary Regression. The deformation of the roadway during the roadway excavation is affected by the physical and mechanical properties of the surrounding rock, the magnitude of the in situ stress, the shape and size of the roadway section, the excavation technology, and support scheme, but it is not affected by mining. Firstly, the functional relationship between the displacement convergence in surrounding rock of roadway and each index during excavating is established, and then the relationship between the displacement convergence in surrounding rock of roadway and each index during the mining is established.

\subsubsection{The Functional Relationship between the Displacement Convergence in Surrounding Rock of Roadway and Each Index during Excavating}

(1) The functional relationship between the displacement convergence in surrounding rock of roadway and the comprehensive strength of surrounding rock during excavating:

According to field measured data and nonlinear regression, the relationship between the roof-to-floor convergence (rib-to-rib convergence) of roadway and the comprehensive strength of surrounding rock is established, as shown in Figure 2.

$\varepsilon_{v}$ represents the roof-to-floor displacement convergence of the roadway. $\varepsilon_{h}$ represents the rib-to-rib displacement convergence of the roadway. $R_{r z}$ represents the comprehensive strength of the roof, MPa. ${ }_{b r z}$ represents the comprehensive strength of rib, MPa. $R_{r z}$ represents the comprehensive strength of the floor, MPa. $\sigma_{v}$ represents the vertical in situ stress, MPa. $\sigma_{h}$ represents the horizontal in situ stress, $\mathrm{MPa}$.

(2) The functional relationship between the displacement convergence in surrounding rock of roadway and the in situ stress during excavating

Based on field measurement, the relationship between the displacement convergence in surrounding rock of roadway and the in situ stress is established, as shown in Figures 3 and 4.

3.1.2. The Functional Relationship between the Convergence in Surrounding Rock of Roadway and Each Index during Mining. The surrounding rock of the roadway is affected by the front abutment pressure caused by mining. The confining pressure of roadway increases which exceeds the deformation of the roadway during excavating. Similarly, based on field measurement, unary regression is used to establish the relationship between the displacement convergence in surrounding rock of the roadway and each index; the result is shown in Table 2.

3.2. Multiple Regression. The deformation of the roadway is composed of the deformation during excavation and during mining, so the total deformation of the roadway is the sum of these two deformations, and the total displacement convergence in surrounding of roadway is also the sum of these two displacement convergences.

Therefore, the fitting equation for the roof-to-floor displacement convergence of the roadway is obtained as follows: 


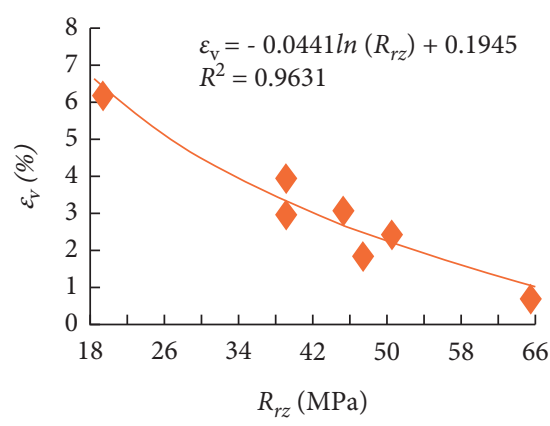

(a)

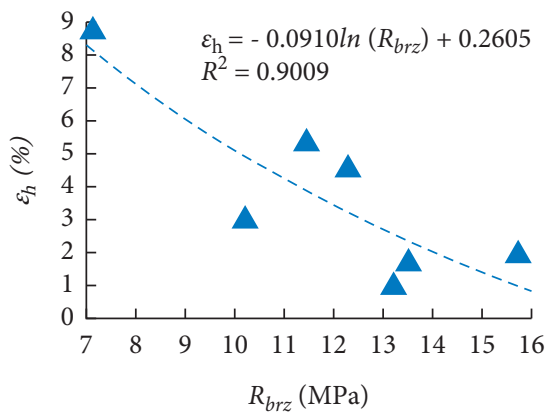

(d)

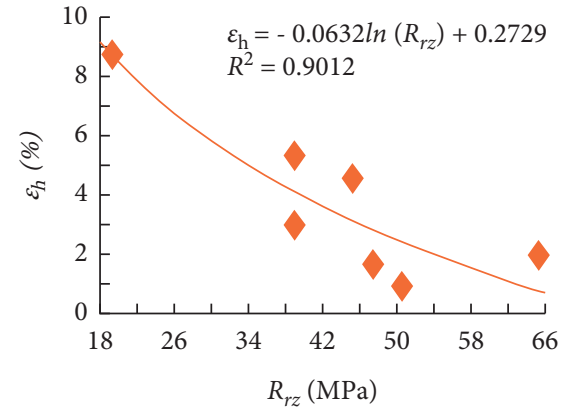

(b)

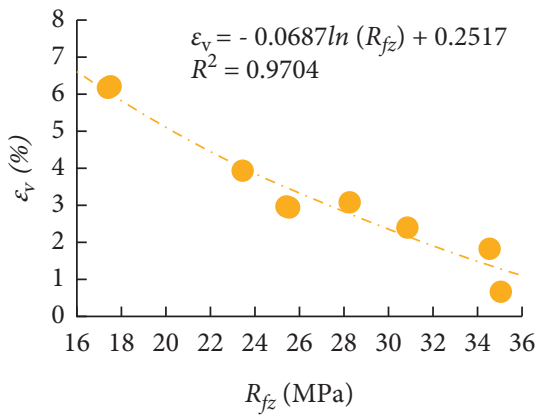

(e)

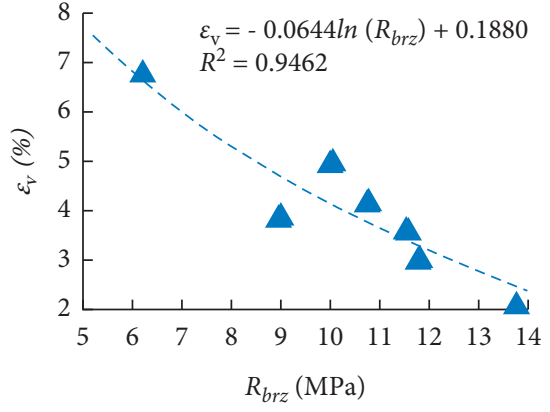

(c)

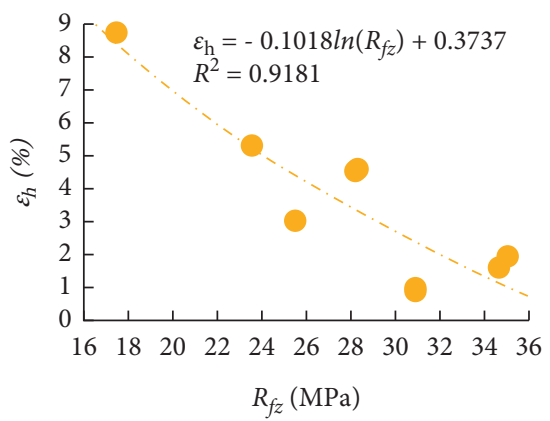

(f)

FIGURE 2: Statistical relationship between comprehensive strength and displacement convergence of coal roadway.

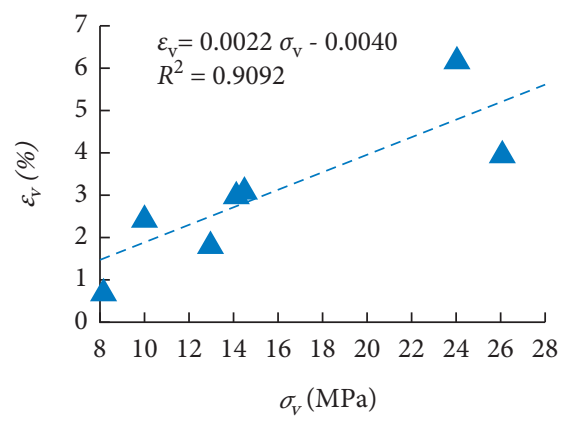

(a)

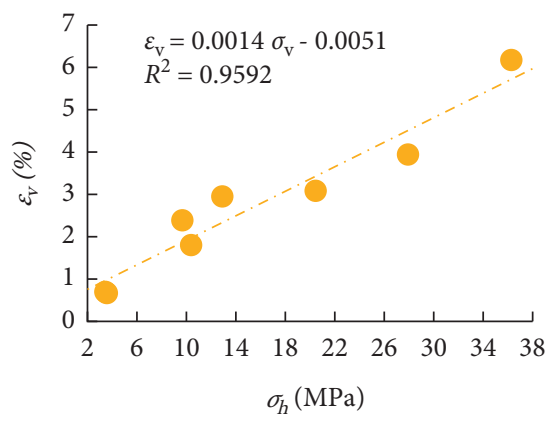

(b)

FIGURE 3: Statistical relationship between in situ stress and roof-to-floor displacement convergence of roadway.

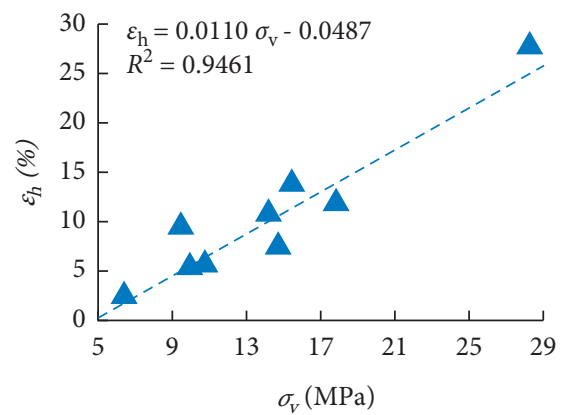

(a)

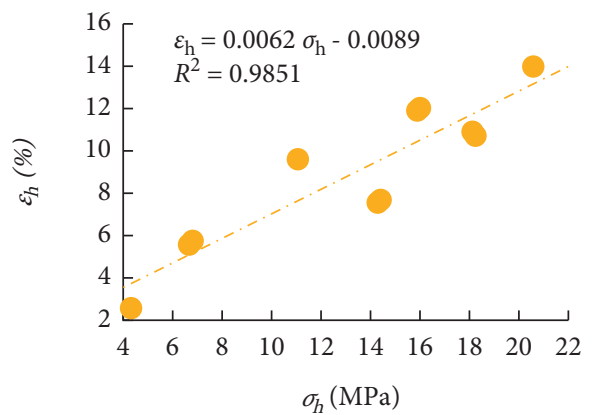

(b)

FIgURE 4: Statistical relationship between in situ stress and rib-to-rib displacement convergence of roadway. 
TABLE 2: Fitting equations between each index and displacement convergence of the coal roadway.

\begin{tabular}{|c|c|c|c|}
\hline Displacement convergence & Classification index & Fitting relation & Correlation coefficient \\
\hline \multirow{7}{*}{$\varepsilon_{v}$} & $R_{r z}$ & $\varepsilon_{v}=-0.12 \ln \left(R_{r z}\right)+0.49$ & $R^{2}=0.93$ \\
\hline & $R_{b r z}$ & $\varepsilon_{v}=-0.13 \ln \left(R_{b z}\right)+0.40$ & $R^{2}=0.95$ \\
\hline & $R_{f z}$ & $\varepsilon_{v}=-0.09 \ln \left(R_{f z}\right)+0.39$ & $R^{2}=0.91$ \\
\hline & $\sigma_{v}$ & $\varepsilon_{v}=0.01 \sigma_{v}-0.01$ & $R^{2}=0.95$ \\
\hline & $\sigma_{h}$ & $\varepsilon_{v}=0.01 \sigma_{h}+0.02$ & $R^{2}=0.91$ \\
\hline & $N$ & $\varepsilon_{v}=0.05 N+0.04$ & $R^{2}=0.90$ \\
\hline & $C_{0}$ & $\varepsilon_{v}=-0.19 \ln \left(C_{0}\right)+0.04$ & $R^{2}=0.92$ \\
\hline \multirow{7}{*}{$\varepsilon_{h}$} & $R_{r z}$ & $\varepsilon_{h}=-0.15 \ln \left(R_{r z}\right)+0.60$ & $R^{2}=0.90$ \\
\hline & $R_{b r z}$ & $\varepsilon_{h}=-0.17 \ln \left(R_{b r z}\right)+0.51$ & $R^{2}=0.94$ \\
\hline & $R_{f z}$ & $\varepsilon_{h}=-0.13 \ln \left(R_{f z}\right)+0.51$ & $R^{2}=0.91$ \\
\hline & $\sigma_{v}$ & $\varepsilon_{h}=0.01 \sigma_{v}-0.05$ & $R^{2}=0.92$ \\
\hline & $\sigma_{h}$ & $\varepsilon_{h}=0.01 \sigma_{h}+0.01$ & $R^{2}=0.93$ \\
\hline & $N$ & $\varepsilon_{v}=0.06 N+0.04$ & $R^{2}=0.90$ \\
\hline & $C_{0}$ & $\varepsilon_{v}=-0.20 \ln \left(C_{0}\right)+0.76$ & $R^{2}=0.93$ \\
\hline
\end{tabular}

$N$ represents the immediate roof backfilled ratio. $C_{0}$ represents the main roof first weighting interval.

$$
\begin{aligned}
\varepsilon_{v}= & -0.12 \ln \left(R_{r z}\right)+0.02 \ln \left(R_{b r z}\right)-0.09 \ln \left(R_{f z}\right) \\
& +0.01 \sigma_{h}-0.01 \sigma_{v}-0.14 \ln \left(C_{0}\right)-0.03 N+1.28 .
\end{aligned}
$$

Similarly, the fitting formula of rib-to-rib displacement convergence of roadway is obtained as follows:

$$
\begin{aligned}
\mathcal{E}_{h}= & -0.02 \ln \left(R_{r z}\right)+0.10 \ln \left(R_{b r z}\right)-0.08 \ln \left(R_{f z}\right) \\
& +0.02 \sigma_{h}-0.01 \sigma_{v}-0.06 \ln \left(C_{0}\right)-0.02 N+0.30 .
\end{aligned}
$$

With the fitting equation of displacement convergence in surrounding rock of roadway, it is possible to predict the deformation of the surrounding rock of roadway based on the comprehensive strength of surrounding rock, in situ stress, the immediate roof backfilled ratio, and the main roof first weighting interval, combined with the size of roadway.

\section{Surrounding Rock Stability Classification of Coal Roadway Based on Fuzzy Clustering}

4.1. Determination of the Optimal Classification Number. The fuzzy clustering process of surrounding rock stability classification is shown in Figure 5. After fuzzy clustering, it is necessary to determine the optimal number of coal roadway classification.

Transforming each classification index into a comprehensive index according to the weight is expressed by the displacement convergence of surrounding rock. According to the basic principle of fuzzy clustering [26], with the different values of $\lambda$, the classification results are also different; the optimal classification results can be selected according to F-statistics. The calculation formula of F-statistics is

$$
F=\frac{\sum_{i=1}^{r}\left(\overline{y_{i 0}}-\overline{y_{00}}\right)^{2} /(r-1)}{\sum_{i=1}^{r} \sum_{j=1}^{n}\left(y_{i j}-y_{i 0}\right)^{2} /(n-r)} .
$$

For the fuzzy clustering process, when the classification result changes from 2 to 12 , each $F$ value and its $F_{0.05}$ value (under 0.05 confidence) level are shown in Tables 3 and 4. According to mathematical statistics analysis, if $F>F_{0.05}$, the difference between classes is significant; that is, the classification result is reasonable.

It can be seen in Tables 3 and 4 that when $\lambda=0.75$, $F-F_{0.05}$ is the maximum of all classifications, so the fuzzy clustering result of $\lambda=0.75$ is the best; that is, the coal seam roadway samples are clustered into four categories.

4.2. Surrounding Rock Stability Classification Results of Coal Roadway. Based on the results of fuzzy cluster analysis and empirical evaluation, the surrounding rock of 37 coal roadways is divided into four categories, which are very stable (I), relatively stable (II), medium stable (III), and unstable (IV). The displacement convergence in surrounding rock of each type of roadway is predicted, and the final classification results of surrounding rock stability are shown in Table 5.

4.3. Field Application: Taking Class IV Surrounding Rock for Example. According to the SIM surrounding rock stability classification results of the above 37-roadway sample data, the No.3302 roadway with typical geological and mining conditions was selected for the industrial test in the class IV unstable surrounding rock, and the support effect of the No.2306 roadway under similar geological conditions was compared to verify the rationality of the SIM surrounding rock stability classification results based on the in situ stress.

According to the geological conditions of the roadway No.3302, through laboratory test and field test, the results of each evaluation index determination are shown in Table 6.

According to the results of the SIM surrounding rock stability classification (Table 5), the surrounding rock of the No.3302 roadway belongs to the class IV unstable surrounding rock. 


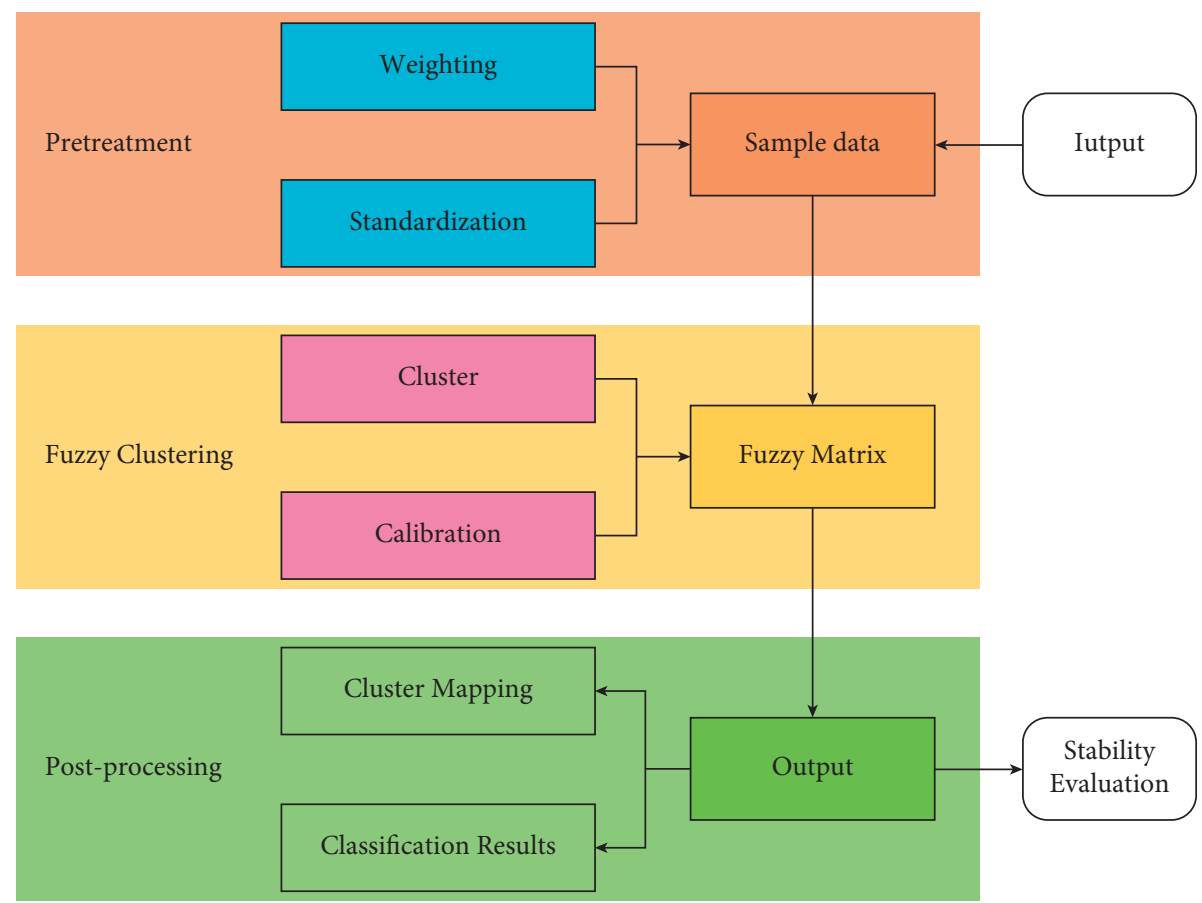

FIGURE 5: Fuzzy clustering process of surrounding rock stability classification.

TABLE 3: Selection comparison table of $\lambda$ (according to roof-to-floor convergence).

\begin{tabular}{lccccccc}
\hline Items & 2 & 3 & 4 & 5 & 6 & 7 \\
\hline$\lambda$ & 0.65 & 0.70 & 0.75 & 0.77 & 0.80 & 0.85 & 0.89 \\
$F$ & 3.89 & 2.99 & 3.79 & 2.87 & 3.18 & 2.86 \\
$F_{0.05}$ & 4.14 & 3.25 & 2.86 & 2.67 & 2.50 & 2.70 \\
$F-F_{0.05}$ & -0.26 & -0.25 & 0.93 & 0.20 & 0.68 & 0.47 & 2.25 \\
\hline
\end{tabular}

TABLE 4: Selection comparison table of $\lambda$ (according to rib-to-rib displacement convergence).

\begin{tabular}{lcccccc}
\hline Items & 2 & 3 & 4 & 6 & 7 & 0.85 \\
\hline$\lambda$ & 0.70 & 0.74 & 0.75 & 0.80 & 0.87 \\
$F$ & 2.27 & 3.43 & 13.72 & 3.01 & 2.87 & 2.11 \\
$F_{0.05}$ & 4.14 & 3.25 & 2.86 & 2.50 & 2.39 & 0.28 \\
$F-F_{0.05}$ & -1.87 & 0.18 & 10.86 & 0.51 & -0.17 \\
\hline
\end{tabular}

TABLE 5: Classification results of surrounding rock stability of coal roadway.

\begin{tabular}{|c|c|c|c|c|c|c|c|c|c|}
\hline \multirow{2}{*}{ Grade } & \multicolumn{3}{|c|}{ Strength of surrounding rock } & \multicolumn{2}{|c|}{ In situ stress } & \multirow{2}{*}{$\begin{array}{c}N \\
(\mathrm{M})\end{array}$} & \multirow{2}{*}{$\begin{array}{l}C_{0} \\
(\%) \\
\end{array}$} & \multicolumn{2}{|c|}{$\begin{array}{c}\text { Displacement convergence } \\
\text { prediction }\end{array}$} \\
\hline & $\begin{array}{l}\text { Roof } \\
(\mathrm{MPa})\end{array}$ & $\begin{array}{l}\text { Rib } \\
(\mathrm{MPa})\end{array}$ & $\begin{array}{l}\text { Floor } \\
(\mathrm{MPa})\end{array}$ & $\begin{array}{c}\sigma_{v} \\
(\mathrm{MPa})\end{array}$ & $\begin{array}{c}\sigma_{h} \\
(\mathrm{MPa})\end{array}$ & & & $\begin{array}{l}\text { Roof-to-floor } \\
(\%)\end{array}$ & $\begin{array}{l}\text { Rib-to-rib } \\
\quad(\%)\end{array}$ \\
\hline I, very stable & $>50.5$ & $>15.3$ & $>38.5$ & $<8.9$ & $<9.6$ & $<0.6$ & $>34$ & $<6.0$ & $<5.6$ \\
\hline II, relatively stable & $31.8 \sim 50.5$ & $10.4 \sim 15.3$ & $25.4 \sim 38.5$ & $8.9 \sim 15.6$ & $9.6 \sim 20.0$ & $\begin{array}{c}0.6 \sim \\
1.4\end{array}$ & $27.2 \sim 34.0$ & $6.0 \sim 13.5$ & $5.6 \sim 15.4$ \\
\hline III, medium stable & $18.3 \sim 31.8$ & $6.8 \sim 10.4$ & $14.6 \sim 25.4$ & $15.6 \sim 27.8$ & $20.0 \sim 32.4$ & $\begin{array}{c}1.4 \sim \\
2.4\end{array}$ & $21.0 \sim 27.2$ & $13.5 \sim 19.5$ & $15.4 \sim 25$ \\
\hline IV, unstable & $<18.3$ & $<6.8$ & $<14.6$ & $>27.8$ & $>32.4$ & $>2.4$ & $<21.0$ & $>19.5$ & $>25.0$ \\
\hline
\end{tabular}


TABLE 6: Determination results of surrounding rock stability evaluation index of No.3302 roadway.

\begin{tabular}{lcccccrr}
\hline Evaluation index & $\begin{array}{c}R_{r z} \\
(\mathrm{MPa})\end{array}$ & $\begin{array}{c}R_{b r z} \\
(\mathrm{MPa})\end{array}$ & $\begin{array}{c}R_{f z} \\
(\mathrm{MPa})\end{array}$ & $\begin{array}{c}\sigma_{v} \\
(\mathrm{MPa})\end{array}$ & $\begin{array}{c}\sigma_{h} \\
(\mathrm{MPa})\end{array}$ & $\begin{array}{c}C_{0} \\
(\mathrm{~m})\end{array}$ \\
\hline Value & 18.9 & 7.2 & 12.3 & 26.3 & 29.1 & 2.7 \\
\hline
\end{tabular}

TABLE 7: Support scheme before and after optimization of No.3302 roadway.

\begin{tabular}{|c|c|c|c|c|}
\hline \multirow{2}{*}{ Type of surrounding rock } & \multirow{2}{*}{\multicolumn{2}{|c|}{ Support way }} & \multicolumn{2}{|c|}{ Support parameters } \\
\hline & & & Primary support & Reinforced support \\
\hline \multirow{3}{*}{ Roof } & \multirow{3}{*}{ Anchor bolt } & Diameter/mm & 20 & 20 \\
\hline & & Length/mm & 2400 & 2200 \\
\hline & & Spacing/mm & $800 \times 1000$ & $700 \times 700$ \\
\hline \multirow{6}{*}{ Rib } & \multirow{3}{*}{ Anchor bolt } & Diameter/mm & 20 & 20 \\
\hline & & Length/mm & 2200 & 2200 \\
\hline & & Spacing/mm & $800 \times 1000$ & $700 \times 700$ \\
\hline & \multirow{3}{*}{ Anchor cable } & Diameter/mm & 17.8 & 17.8 \\
\hline & & Length/mm & 7000 & 7000 \\
\hline & & Spacing/mm & 1000 & 1000 \\
\hline
\end{tabular}

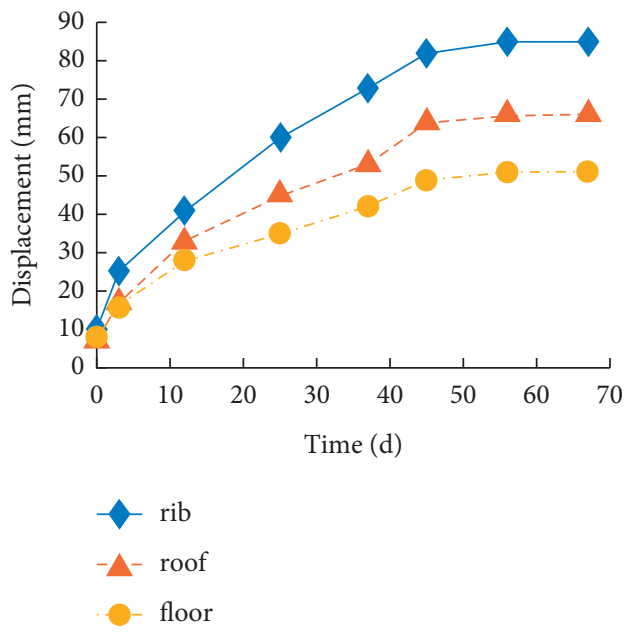

(a)

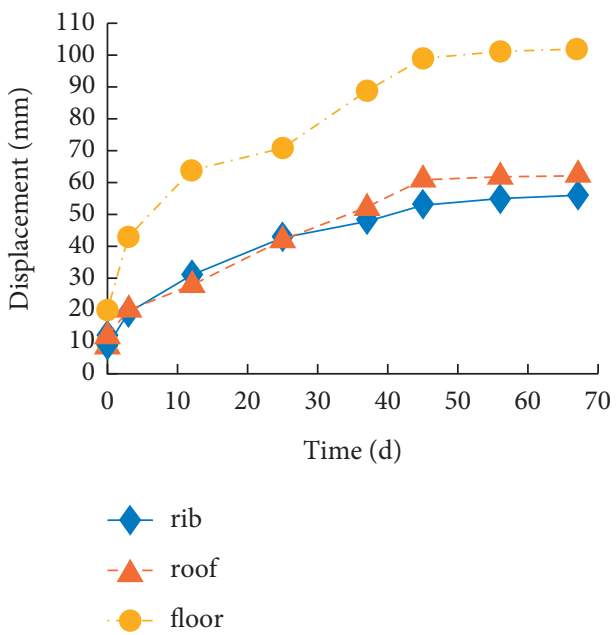

(b)

Figure 6: Surrounding rock deformation of No.3302 coal roadway. (a) 1\# measuring point. (b) 3\# measuring point.

4.3.1. Optimization of the Support Scheme. The original support parameters of No.3302 roadway were determined by engineering analogy method, namely, the support parameters of No.2306 roadway under similar geological conditions. However, the test results show that the in situ stress of the two roadways is quite different. At this time, the roadway support scheme No.3302 using the engineering analogy method is unreasonable and unscientific. Therefore, according to the classification results of surrounding rock stability of SIM based on in situ stress, the support scheme of the No.3302 roadway was optimized, and the support scheme of No.3302 roadway before and after optimization is shown in Table 7.

4.3.2. On-Site Monitoring. To verify the SIM reasonableness of the classification results of the SIM surrounding rock stability and the effectiveness of the optimized support scheme, we conducted on-site monitoring of the No.3302 roadway surrounding rock deformation with 10 measurement points, among which the monitoring results of $1 \#$ measuring point and $3 \#$ measuring point are shown in Figure 6.

From Figure 6, the deformation of the surrounding rocks in No.3302 roadway gradually increases, and displacement convergence gradually decreases, with the maximum convergence of $85 \mathrm{~mm}$ for the rib-to-rib and $165 \mathrm{~mm}$ for the roof-to-floor, which is smaller than the maximum convergence of the surrounding rocks in No.2306 roadway (236 $\mathrm{mm}$ for the rib-to-rib and $452 \mathrm{~mm}$ for the roof-tofloor). The above monitoring results show that the optimized roadway support scheme effectively controls the surrounding rock deformation and proves the reasonableness of the SIM surrounding rock stability classification method based on the in situ stress. 


\section{Conclusion}

(1) Among the many factors that affect the stability of the surrounding rock, the evaluation indexes of coal roadway are determined, including comprehensive strength of surrounding rock (roof, rib, floor), in situ stress $\left(\sigma_{v}, \sigma_{h}\right)$, and mining index (the immediate roof backfilled ratio $N$, the main roof first weighting interval $C_{0}$, and the type of chain pillar).

(2) A method for calculating the strength of surrounding rock is proposed, which combines the strength of the rock block, the rock mass strength coefficient, the thickness of roof coal seam, and floor. The strength of roof (and rib and floor) of coal roadway is determined by thickness weighted average method, which solves the problem of selection of strength index in surrounding rock classification of roadway.

(3) The fitting equation between each evaluation index and the displacement convergence in surrounding rock of coal roadway was determined by unary regression and multiple regression, and the weight of each classification index was determined. On the basis of this fitting equations, the deformation of the surrounding rock of coal roadway can be predicted.

(4) Based on the principle of fuzzy clustering, the fuzzy clustering model of surrounding rock stability classification of coal roadway is established. 37 typical coal roadways to be classified are reasonably divided into four categories: very stable, relatively stable, medium stable, and unstable.

\section{Data Availability}

The data used to support the findings of this study are available from the corresponding author upon request.

\section{Conflicts of Interest}

The authors declare that they have no conflicts of interest.

\section{Acknowledgments}

This research was funded by the National Natural Science Foundation of China (Grant nos. 51574156 and 52074166).

\section{References}

[1] H. P. Kang and J. H. Wang, Rock Bolting Theory and Complete Technology for Coal Roadways, China Coal Industry Publishing House, Beijing, China, 2018.

[2] D. U. Deere, "Technical description of rock cores for engineering purpose," Rock Mechanics and Enginee-ring Geology, vol. 1, no. 1, pp. 17-22, 1964.

[3] D. U. Deere, A. J. Hendron, F. D. Patton, and E. J. Cording, "Design of surface and near-surface construction in rock," in Proceedings of the 8th US symposium on rock mechanics (USRMS), Minneapolis, MN, USA, September 1966.

[4] D. U. Deere, "Rock quality designation (RQD) after twenty years," Contract Report GL-89-1, Deere Consultant, Gainesville, FL, USA, 1989.
[5] Z. T. Bieniawski, "Engineering classification of jointed rock masses," Civil Engineering Siviele Ingenieurswese, vol. 15, no. 12, pp. 335-343, 1973.

[6] Z. T. Bieniawski, "Determining rock mass deformability: experience from case histories," International Journal of Rock Mechanics and Mining Science \& Geomechanics Abstracts, vol. 15, no. 5, pp. 237-247, 1978.

[7] E. Hoek and E. T. Brown, "Practical estimates of rock mass strength," International Journal of Rock Mechanics and Mining Sciences, vol. 34, no. 8, pp. 1165-1186, 1997.

[8] N. Barton, F. Løset, R. Lien, and J. Lunde, "Application of Q-system in design decisions concerning dimensions and appropriate support for underground installations," Subsurface Space, vol. 2, pp. 553-561, 1981.

[9] N. Barton, "Some new Q-value correlations to assist in site characterisation and tunnel design," International Journal of Rock Mechanics and Mining Sciences, vol. 39, no. 2, pp. 185-216, 2002.

[10] S.-S. Shi, S.-C. Li, L.-P. Li, Z.-Q. Zhou, and J. Wang, "Advance optimized classification and application of surrounding rock based on fuzzy analytic hierarchy process and Tunnel Seismic Prediction," Automation in Construction, vol. 37, pp. 217-222, 2014.

[11] N. Hasegawa, S. Hasegawa, T. Kitaoka, and H. Ohtsu, “Applicability of neural network in rock classification of mountain tunnel," Materials Transactions, vol. 60, no. 5, pp. 758-764, 2019.

[12] G. Deng and Y. Fu, "Fuzzy rule based classification method of surrounding rock stability of coal roadway using artificial intelligence algorithm," Journal of Intelligent and Fuzzy Systems, vol. 40, no. 4, pp. 8163-8171, 2021.

[13] X. H. Li and Q. Wang, "Prediction of surrounding rock classification of highway tunnel based on PSO-SVM," in Proceedings of the International Conference on Robots and Intelligent System (ICRIS), pp. 443-446, Peoples R China, Haikou, China, June 2019.

[14] S. Zheng, A. N. Jiang, X. R. Yang, and G. C. Luo, "A new reliability rock mass classification method based on least squares support vector machine optimized by bacterial foraging optimization algorithm," Advances in Civil Engineering, vol. 2020, Article ID 3897215, 13 pages, 2020.

[15] Y. Wang, N. Zhao, H. Jing, B. Meng, and X. Yin, "A novel model of the ideal point method coupled with objective and subjective weighting method for evaluation of surrounding rock stability," Mathematical Problems in Engineering, vol. 2016, Article ID 8935156, 9 pages, 2016.

[16] M. Wang, X. Xu, J. Li, J. Jin, and F. Shen, "A novel model of set pair analysis coupled with extenics for evaluation of surrounding rock stability," Mathematical Problems in Engineering, vol. 2015, Article ID 892549, 9 pages, 2015.

[17] H. He, Y. Yan, C. Qu, and Y. Fan, "Study and application on stability classification of tunnel surrounding rock based on uncertainty measure theory," Mathematical Problems in Engineering, vol. 2014, Article ID 626527, 5 pages, 2014.

[18] S. Wu, S. Yang, and X. Du, "A model for evaluation of surrounding rock stability based on D-S evidence theory and erroreliminating theory," Bulletin of Engineering Geology and the Environment, vol. 80, no. 3, pp. 2237-2248, 2021, (in English).

[19] X. Liu, D. Fan, Y. Tan et al., "New detecting method on the connecting fractured zone above the coal face and a case study," Rock Mechanics and Rock Engineering, vol. 54, no. 8, pp. 4379-4391, 2021.

[20] X. Liu, S. Song, Y. Tan et al., "Similar simulation study on the deformation and failure of surrounding rock of a large section 
chamber group under dynamic loading," International Journal of Mining Science and Technology, vol. 31, no. 3, pp. 495-505, 2021.

[21] Y. Xue, Z. Li, D. Qiu et al., "Classification model for surrounding rock based on the PCA-ideal point method: an engineering application," Bulletin of Engineering Geology and the Environment, vol. 78, no. 5, pp. 3627-3635, 2019.

[22] P. He, L. P. Li, Q. Q. Zhang, F. Xu, J. Hu, and J. Zhang, "Gaussian process model of an advanced surrounding rock classification based on tunnel seismic predictions," in Proceedings of the Fourth Geo-China International Conference on Sustainable Civil Infrastructures - Innovative Technologies for Severe Weathers and Climate Changes, pp. 210-217, Shangdong, China, July 2016.

[23] P. He, S.-C. Li, L.-P. Li, Q.-Q. Zhang, F. Xu, and Y.-J. Chen, "Discontinuous deformation analysis of super section tunnel surrounding rock stability based on joint distribution simulation," Computers and Geotechnics, vol. 91, pp. 218-229, 2017.

[24] P. He, S. Q. Sun, G. Wang, and W.-T. Li, "Gaussian process model of surrounding rock classification based on digital characterization of rock mass structure and its application," Mathematical Problems in Engineering, vol. 2020, Article ID 5264072, 15 pages, 2020.

[25] G. C. Zhang, Z J. Wen, S. J. Liang et al., "Ground response of a gob-side entry in a longwall panel extracting $17 \mathrm{~m}$-thick coal seam: a case study," Rock Mechanics and Rock Engineering, vol. 53, pp. 497-516, 2020.

[26] G. C. Zhang, C W. Zang, M. Chen et al., "Ground response of entries driven adjacent to a retreating longwall panel," International Journal of Rock Mechanics and Mining Sciences, vol. 138, p. 104630, 2021.

[27] Y. Liu, C. Hou, J. Yao et al., "Classification scheme of surrounding rock stability of mining roadway in slowly inclined and inclined coal seams in China," Coal Science and Technology, vol. 6, pp. 2-6, 1988. 